\title{
Interfacial Properties of CZTS Thin Film Solar Cell
}

\author{
N. Muhunthan, ${ }^{1}$ Om Pal Singh, ${ }^{1}$ M. K. Thakur, ${ }^{1}$ P. Karthikeyan, ${ }^{1}$ \\ Dinesh Singh, ${ }^{2}$ M. Saravanan, ${ }^{3}$ and V. N. Singh ${ }^{1,2}$ \\ ${ }^{1}$ Compound Semiconductor Solar Cell Section, Physics of Energy Harvesting Division, CSIR-National Physical Laboratory, \\ Dr. K. S. Krishnan Marg, New Delhi 110012, India \\ ${ }^{2}$ Electron and Ion Microscopy Section, Sophisticated and Analytical Instruments Division, CSIR-National Physical Laboratory, \\ Dr. K. S. Krishnan Marg, New Delhi 110012, India \\ ${ }^{3}$ Metals and Alloys Group, Materials Physics and Engineering Division, CSIR-National Physical Laboratory, \\ Dr. K. S. Krishnan Marg, New Delhi 110012, India
}

Correspondence should be addressed to V. N. Singh; vidyanands@yahoo.com

Received 16 September 2014; Revised 10 November 2014; Accepted 10 November 2014; Published 26 November 2014

Academic Editor: Paulo Fernandes

Copyright (c) 2014 N. Muhunthan et al. This is an open access article distributed under the Creative Commons Attribution License, which permits unrestricted use, distribution, and reproduction in any medium, provided the original work is properly cited.

\begin{abstract}
$\mathrm{Cu}$-deficient CZTS (copper zinc tin sulfide) thin films were grown on soda lime as well as molybdenum coated soda lime glass by reactive cosputtering. Polycrystalline CZTS film with kesterite structure was produced by annealing it at $500^{\circ} \mathrm{C}$ in $\mathrm{Ar}$ atmosphere. These films were characterized for compositional, structural, surface morphological, optical, and transport properties using energy dispersive X-ray analysis, glancing incidence X-ray diffraction, Raman spectroscopy, scanning electron microscopy, atomic force microscopy, UV-Vis spectroscopy, and Hall effect measurement. A CZTS solar cell device having conversion efficiency of $\sim 0.11 \%$ has been made by depositing CdS, ZnO, ITO, and Al layers over the CZTS thin film deposited on Mo coated soda lime glass. The series resistance of the device was very high. The interfacial properties of device were characterized by cross-sectional SEM and cross-sectional HRTEM.
\end{abstract}

\section{Introduction}

The optical and electronic properties of CZTS make it a suitable absorber layer for thin film photovoltaic. CZTS made from earth abundant and nontoxic elements is an ideal candidate to replace $\mathrm{Cu}(\mathrm{In}, \mathrm{Ga}) \mathrm{Se}_{2}$ (CIGS) and $\mathrm{CdTe}$ which face material scarcity and toxicity issues for large scale production of solar cells. Therefore, thin film CZTS solar cell has received great attention in recent years [1-5]. CZTS is reported to have a band gap between 1.40 to $1.50 \mathrm{eV}$ [15] and a band edge absorption coefficient above $10^{4} \mathrm{~cm}^{-1}$ which makes it highly attractive as a single junction solar cell material. Efficiency up to $8.4 \%$ and $12.6 \%$ have been achieved for CZTS [6] and $\mathrm{Cu}_{2} \mathrm{ZnSn}(\mathrm{S}, \mathrm{Se})_{4}$ (CZTS,Se) [7] solar cells, respectively. Efficiency of nearly $6.2 \%$ has been achieved using cosputtering of $\mathrm{Cu}, \mathrm{ZnS}$, and $\mathrm{SnS}$ target in Ar atmosphere [8]. In the case of CIGS and CdTe thin film solar cells, the best efficiency reported is $21.7 \%$ [9] and $20.4 \%$ [10], respectively. The CZTS thin film solar cell device property is affected by the presence of phase impurities like $\mathrm{Cu}_{2} \mathrm{~S}, \mathrm{Cu}_{2} \mathrm{SnS}_{3}, \mathrm{ZnS}, \mathrm{SnS}$, and so on and poor quality of interfaces [11-14]. The open circuit voltage of the device which depends on the career generation and recombination process is controlled by the presence of defects [15-18]. The poor interfacial properties also affect the performance of the device $[19,20]$.

Generally, two-step process is used for the deposition of CZTS thin film (metallic film deposition and then sulfurization). In the two-step process, during sulfurization, the film surface becomes rough which may hinder the formation of proper junction when n-type CdS is coated over it and also there is loss of Sn due to high temperature processing. Thus, process conditions like annealing time and temperature need to be optimized. A small variation in time, temperature, and thickness of films may lead to the formation of secondary or tertiary phases. The samples deposited by reactive cosputtering process shall have smoother surface. There are only three reports on the deposition of CZTS thin 
films by reactive cosputtering. In one study, Liu et al. have deposited CZTS thin film by reactive cosputtering and have reported only the structural, optical, and electrical properties of the film [21]. In another study, Li et al. have shown a device efficiency of $3.37 \%$. Apart from deposition of CZTS thin film, by reactive cosputtering (with $50 \% \mathrm{H}_{2} \mathrm{~S}$ ), all the other layers were deposited at NREL [22]. They have studied the current conduction in the device using the scanning probe microscopy technique. In the third reported study, Scragg et al. have reported the efficiency of $4.6 \%$ for a CZTS solar cell device made by reactive cosputtering with $J_{\text {sc }}$ and $V_{\text {oc }}$ both appearing to be limited by interface recombination [23]. Thus, there is a need to understand the interfaces of the device. In the present study, through cross-sectional HRTEM and SEM studies, it has been shown that the device efficiency of CZTS thin film solar cell deposited by reactive cosputtering is marred by the poor adhesion of the film and the poor quality of the interfaces. If the quality of interfaces can be controlled, then the devices quality can be improved. Also, in the thin film based solar cell as all layers are very thin, there is a chance of material from one layer diffusing into the other and thus affecting the device life. Thus, the device needs to be insulated properly and needs to be carefully protected. Therefore, the present study shall be a stepping stone in realizing CZTS device with higher efficiency.

The CZTS thin film made by reactive cosputtering of $\mathrm{Cu}$, $\mathrm{Zn}$, and $\mathrm{Sn}$ targets in the presence of $\mathrm{H}_{2} \mathrm{~S}$ gas on the soda lime glass was characterized for its compositional, structural, morphological, optical, and electrical transport properties. The device made by depositing other layers, like CdS, i- $\mathrm{ZnO}$, ITO, and Al layers, was characterized thoroughly using the cross-sectional SEM and HRTEM analyses and it has been shown that in order to improve the quality of the device, it is essential to improve the interfaces.

\section{Experiments}

2.1. Film Deposition. For CZTS film deposition, $\mathrm{Cu}$ was sputtered using DC power of $38.5 \mathrm{~W}$ and simultaneously $\mathrm{Sn}$ and $\mathrm{Zn}$ were sputtered using RF power of $65 \mathrm{~W}$ and $100 \mathrm{~W}$, respectively. All the three targets were reactively cosputtered in the presence of $\left[\mathrm{H}_{2} \mathrm{~S}(15 \%)+\mathrm{Ar}(85 \%)\right]$ gas. The thickness of individual elements can be controlled by controlling the power. All the targets were either $99.99 \%$ or more pure. Substrate was kept at $120^{\circ} \mathrm{C}$ and was rotated at $10 \mathrm{rpm}$ for uniform deposition. Deposition was carried out for $1 \mathrm{~h}$ and the thickness of the obtained film was $780 \mathrm{~nm}$ (confirmed by Stylus profiler, cross-sectional SEM, and HRTEM imaging).

Prior to deposition, a base pressure of $1.1 \times 10^{-6} \mathrm{mbar}$ was achieved using turbo molecular pump ( 800 liters per second). The deposition was carried out at a pressure of $5.2 \times$ $10^{-3}$ mbar. Postdeposition annealing was carried out in a sliding horizontal tube furnace for $3 \mathrm{~min}$ at $500^{\circ} \mathrm{C}$. CZTS film on a Mo coated SLG substrate was placed on a ceramic plate and kept inside the quartz tube of the single zone furnace. Furnace was mounted on a sliding rail and thus it can move both ways using an electric switch with a constant speed [24].
TABLE 1: Elemental composition of CZTS thin film as estimated by EDS analysis.

\begin{tabular}{lcccc}
\hline Elements & $\mathrm{Cu}$ & $\mathrm{Zn}$ & $\mathrm{Sn}$ & $\mathrm{S}$ \\
\hline EDS-atomic (\%) & 25.7 & 15.1 & 13.2 & 46 \\
\hline
\end{tabular}

The furnace temperature was increased to $500^{\circ} \mathrm{C}$ with a ramping rate of $20^{\circ} \mathrm{C}$ per min and argon flow rate was set to $30 \mathrm{sccm}$. When the desired temperature was reached, the furnace was moved to the sample area and, after $3 \mathrm{~min}$, it was taken away.

For the device fabrication, prior to CZTS deposition, Mo was deposited as bottom electrode on SLG substrate at $100^{\circ} \mathrm{C}$ by DC magnetron sputtering. The deposition was carried out in two steps. For the first $20 \mathrm{~min}$, deposition was carried out at high pressure and low power (a working pressure of $2.8 \times$ $10^{-2} \mathrm{mbar}$ and DC power @ $30 \mathrm{~W}$ ). For the next $40 \mathrm{~min}$, deposition was carried out at low pressure and high power (working pressure of $1.8 \times 10^{-2} \mathrm{mbar}$ and DC power @ $50 \mathrm{~W}$ ). The thickness of Mo film was $1.2 \mu \mathrm{m}$.

2.2. Characterization. Morphological study of thin film sample was carried out using scanning electron microscope (Zeiss EVO MA10, SEM). Energy dispersive X-ray spectroscopy (EDS) analysis was carried out using EDS attached with the SEM. Glancing incidence X-ray diffraction (GIXRD) study was carried out using Rigaku Miniflex X-ray diffractometer with an incident angle of $1^{\circ}$. Multimode AFM with NanoScope V controller (Veeco Ltd., USA) was used for all AFM studies. Optical properties were studied using UV1800 Shimadzu spectrophotometer. Raman study was carried out using Jobin Yvon T64000, triple monochromator Raman spectrometer with an excitation wavelength of $514.5 \mathrm{~nm}$. Solar cell characteristics were measured using in-house built equipment. Cross-sectional TEM analyses of CZTS solar cell device were carried out by making cross-sectional samples and studying it under transmission electron microscope (HRTEM, FEI G2, F-30, s-twin, The Netherlands) operating at an accelerating voltage of $300 \mathrm{kV}$.

\section{Results and Discussion}

3.1. Chemical Composition. The result of compositional analysis of CZTS sample by EDS is shown in Table 1. The atomic ratio of $[\mathrm{Zn}] /[\mathrm{Sn}]=1.14,[\mathrm{Cu}] /([\mathrm{Zn}]+[\mathrm{Sn}])=0.90$, and $[\mathrm{S}] /[\mathrm{Cu}+\mathrm{Zn}+\mathrm{Sn}]=0.85$. Thus, the CZTS thin film was $\mathrm{Zn}-$ rich and copper deficient, which are reported to have good optoelectronic properties suitable for solar cell application $[21,25]$.

3.2. Structural and Morphological Properties. Figure 1(a) shows the GIXRD pattern of CZTS film. It is clear from the XRD pattern that the CZTS thin film is having good crystallinity (low background and sharp peaks). The high intensity of (112) peak revealed that the growth is preferential. Other observed peaks correspond to (101), (110), (103), (200), (202), (114), (105), (202), (312), and (224) planes of kesterite 


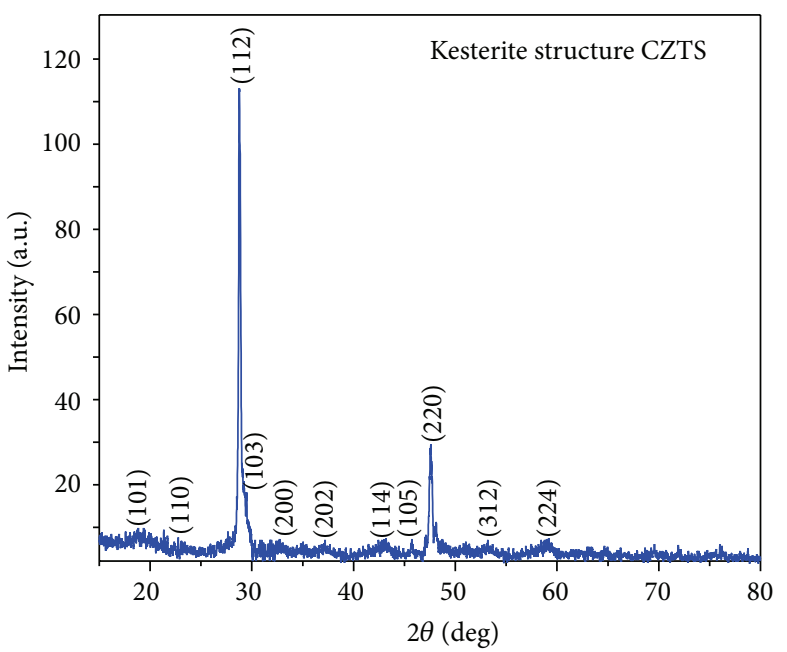

(a)

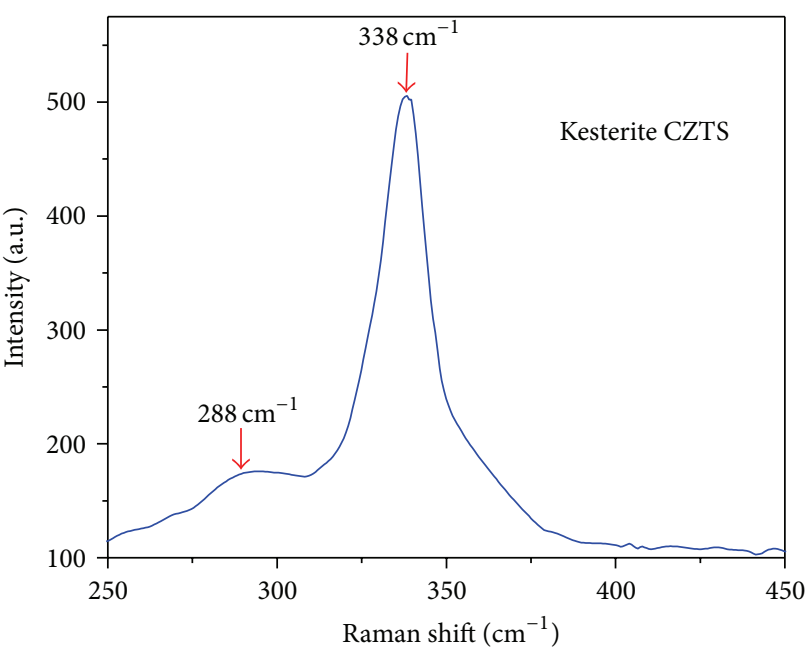

(b)

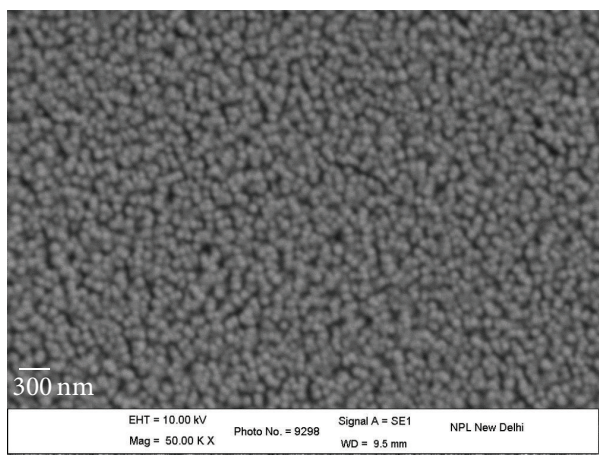

(c)

FIGURE 1: (a) GIXRD pattern, (b) Raman spectrum, and (c) SEM top view of CZTS thin film deposited on SLG.

CZTS (JCPDS 26-0575) [26]. Figure 1(b) shows the Raman spectrum of CZTS film. Raman peaks at 288 and $338 \mathrm{~cm}^{-1}$ correspond to kesterite CZTS [21, 25, 27, 28]. Peaks due to $\mathrm{Cu}_{2} \mathrm{SnS}_{3}, \mathrm{ZnS}$, and $\mathrm{Cu}_{2-x} \mathrm{~S}$ phases were absent in the Raman spectrum. Thus, GIXRD and Raman studies show the pure kesterite nature of CZTS thin film. The SEM micrograph of the surface of the CZTS film is shown in Figure 1(c). Film consists of grains with uniform sizes. This is confirmed by AFM studies.

The AFM topography and the 3D surface visualization of the CZTS thin film deposited on Mo coated SLG are shown in Figures 2(a) and 2(b), respectively. In this measurement, it is possible to get an absolute value for the spatial dimension of the CZTS surface. In Figures 2(a) and 2(b), the topography and $3 \mathrm{D}$ images show granular variations in a very small area $\left(1 \times 1 \mu \mathrm{m}^{2}\right)$.

The detailed features of the grains were not observed in SEM observation, but the interior part of the grains and the deep gaps between the grains are displayed in AFM topography. The root mean square (RMS) roughness $\left(R_{q}\right)$ and the average roughness $\left(R_{a}\right)$ parameter were measured over the line profile scan A-B as shown in Figure 2(c). The maximum $R_{a}$ value of $10.94 \mathrm{~nm}$ and $R_{q}$ value of $8.69 \mathrm{~nm}$ were obtained. The values show that the surface was quite smooth. A relatively smooth surface allows good physical contact with the subsequent layer and avoids the shorting that may arise due to uneven surface topography.

3.3. Optical and Electrical Transport Properties. The optical absorbance curve of CZTS thin film is shown in Figure 3(a). CZTS film is having an optical absorption coefficient $(\alpha)$ higher than $6 \times 10^{4} \mathrm{~cm}^{-1}$ for film having a thickness of $780 \mathrm{~nm}$. Tauc's plot graph is shown in Figure 3(b) and the estimated direct optical band gap of CZTS film is $1.42 \mathrm{eV}$ which is estimated using the intercept of the linear region of the plot $(\alpha h \nu)^{2}$ versus $h v$ on $x$-axis at $\alpha h \nu=0$. This value is quite close to the theoretical optimal value of $1.50 \mathrm{eV}$ for a single junction solar cell $[26,28]$. Electrical transport measurements were carried out in four-probe configuration using Hall effect measurements setup. The resistivity $(\sigma)$ of the CZTS thin film was $1.89 \times 10^{-1} \Omega \mathrm{cm}$. Hall effect measurement was carried out with a magnetic field intensity of $0.5 \mathrm{~T}$ and current of $20 \mu \mathrm{A}$ at room temperature. The hole mobility of CZTS thin film is $1.27 \mathrm{~cm}^{2} \cdot \mathrm{V}^{-1} \cdot \mathrm{s}^{-1}$. The reported values for the hole mobility are in the range of the 1 to 


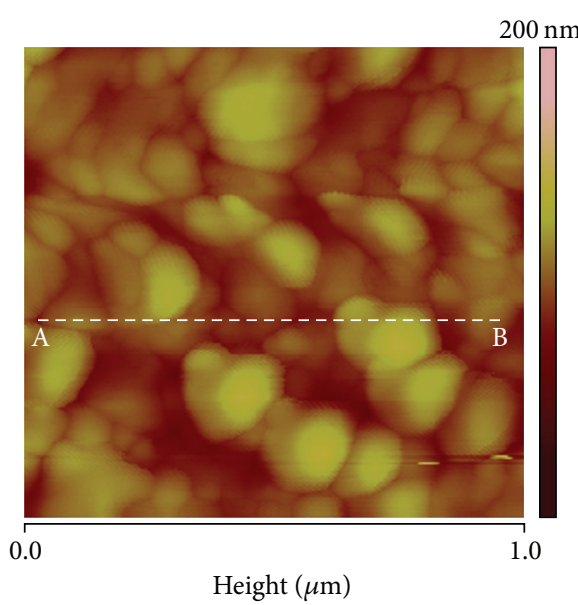

(a)

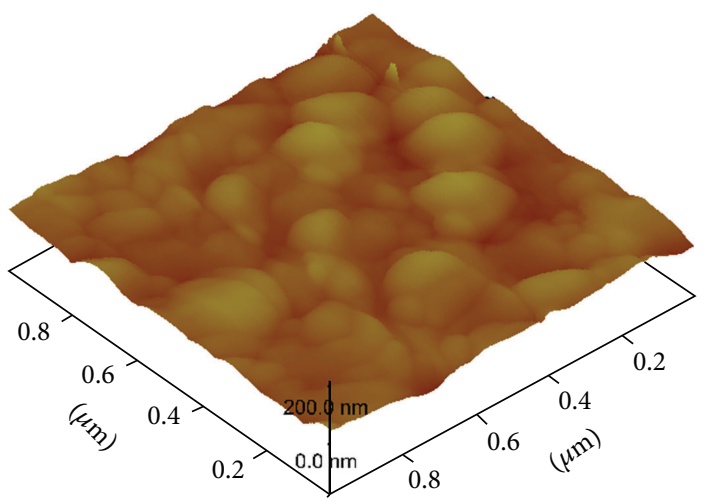

(b)

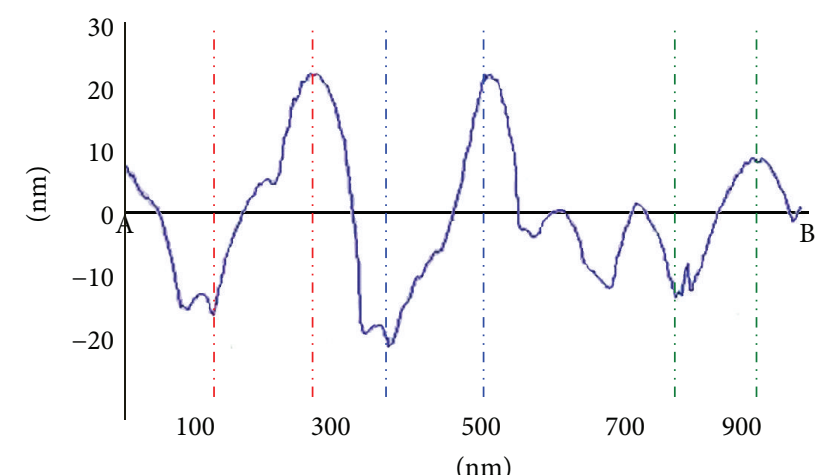

\begin{tabular}{|c|c|c|c|c|c|c|}
\hline Pair & & Horizontal distance & Vertical distance & Surface distance & $R_{q}$ & $R_{a}$ \\
\hline$\checkmark$ & 0 & $0.137 \mu \mathrm{m}$ & $43.881 \mathrm{~nm}$ & $0.146 \mu \mathrm{m}$ & $8.689 \mathrm{~nm}$ & $10.944 \mathrm{~nm}$ \\
\hline$\checkmark$ & 1 & $0.141 \mu \mathrm{m}$ & $37.271 \mathrm{~nm}$ & $0.150 \mu \mathrm{m}$ & $8.610 \mathrm{~nm}$ & $9.753 \mathrm{~nm}$ \\
\hline$\checkmark$ & 2 & $0.118 \mu \mathrm{m}$ & $22.405 \mathrm{~nm}$ & $0.125 \mu \mathrm{m}$ & $8.533 \mathrm{~nm}$ & $7.196 \mathrm{~nm}$ \\
\hline
\end{tabular}

(c)

Figure 2: (a) AFM topograpy, (b) 3D AFM surface visualization, and (c) a line profile of the topography signal from the region A-B from (a). The line scans display the average roughness $\left(R_{a}\right)-10.94 \mathrm{~nm}$ between blue dashed-double dotted lines, the $R_{a}-9.75 \mathrm{~nm}$ between red dashed-double dotted lines, and the $R_{a}-7.19 \mathrm{~nm}$ between green dashed-double dotted lines, respectively, of the Cu-deficient CZTS film.

$10 \mathrm{~cm}^{2} \cdot \mathrm{V}^{-1} \cdot \mathrm{s}^{-1}[26,29,30]$. The hole carrier concentration is approximately $2.55 \times 10^{19} \mathrm{~cm}^{-3}$, which is consistent with other thin film absorber materials where it is reported to vary from $10^{16} \mathrm{~cm}^{-3}$ to $10^{19} \mathrm{~cm}^{-3}[25,30,31]$. The value of Hall coefficient for the CZTS film was $2.45 \times 10^{-1} \mathrm{~cm}^{3} \mathrm{C}^{-1}$. The above compositional, structural, surface morphological, optical, and electrical properties indicate that the CZTS film grown by reactive cosputtering can be used as an absorber layer in thin film solar cells.

3.4. Device Characteristics. For fabrication of CZTS solar cell device, CdS n-type layer was deposited onto the CZTS/Mo layer by $\mathrm{RF}$ sputtering. Insulating $\mathrm{ZnO}$ buffer layer and transparent conducting ITO thin films were subsequently deposited at $150^{\circ} \mathrm{C}$ substrate temperatures by RF sputtering. For top contact, $\mathrm{Al}$ grid was deposited by thermal evaporation.
Current-voltage $(J-V)$ characteristic measured at room temperature is shown in Figure 4. Under dark conditions, there is no contribution from the photogenerated current and the resulting diode characteristic curve is shown as black color in Figure 4. The illuminated characteristic, shown in the same figure (in red color), is merely the dark curve shifted down by a current density $\left(J_{\mathrm{sc}}\right)$. The device showed a short circuit current density $\left(J_{\mathrm{sc}}\right)$ of $6.25 \mathrm{~mA} / \mathrm{cm}^{2}$, an open circuit voltage $\left(V_{\text {oc }}\right)$ of $71.73 \mathrm{mV}$, and a conversion efficiency of $0.11 \%$. The comparatively low efficiency could be attributed to internal deficiency in the CZTS solar cells, such as high contact resistance between CZTS and Mo conductive layers and low interdiffusion between CdS and CZTS interfaces. The low shunt resistance $\left(R_{\mathrm{sh}}-23 \Omega\right)$ results in the lower value of $V_{\text {oc }}$ while the high series resistance $\left(R_{\mathrm{s}}-282 \Omega\right)$ results in lower $J_{\mathrm{sc}}$ and the FF. In order to improve upon the device characteristics, rigorous analyses of the interfaces have 


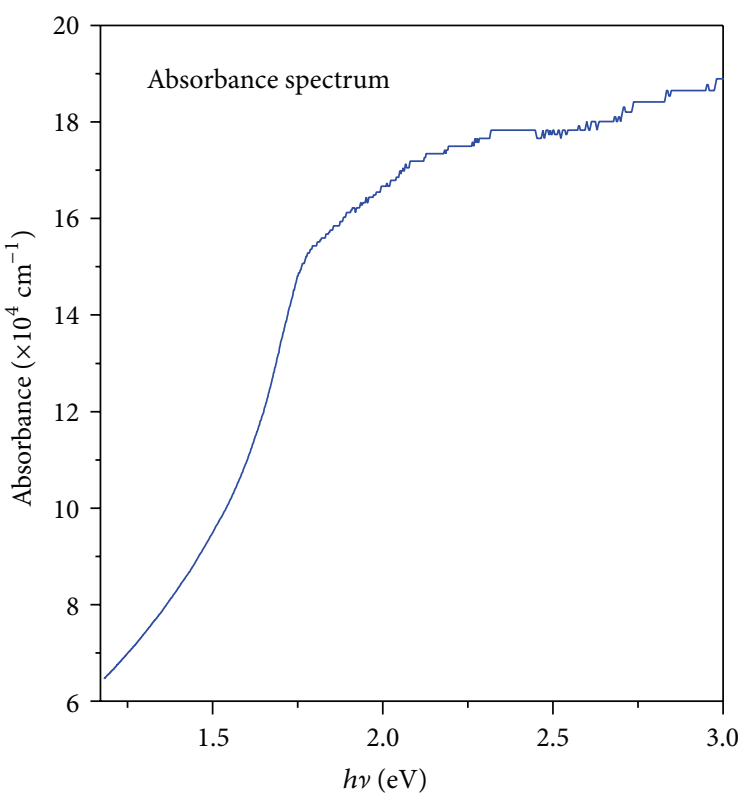

(a)

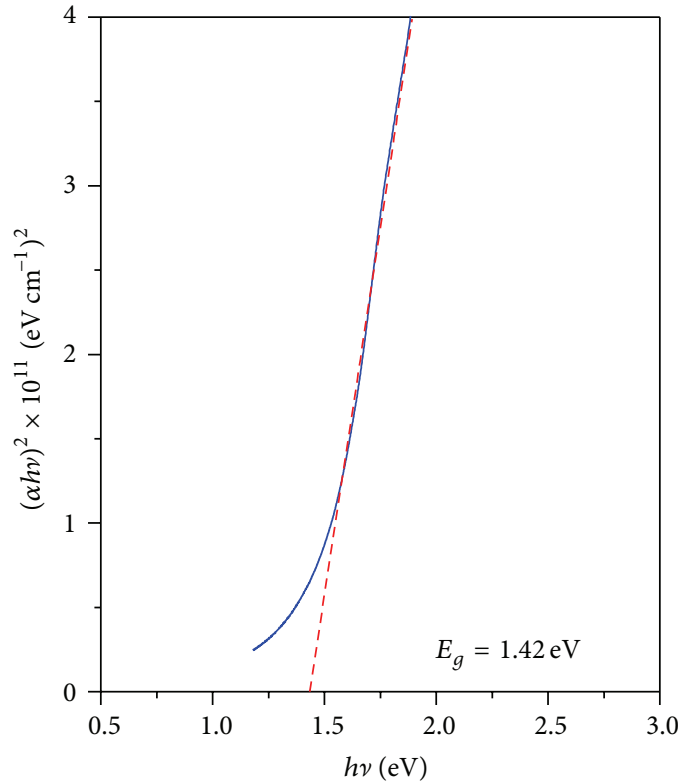

(b)

FIgURE 3: (a) The optical absorbance spectrum of CZTS film on SLG substrate and (b) Tauc's plot: $h \nu$ versus $(\alpha h \nu)^{2}$ for CZTS thin film. The estimated band gap is $1.42 \mathrm{eV}$.

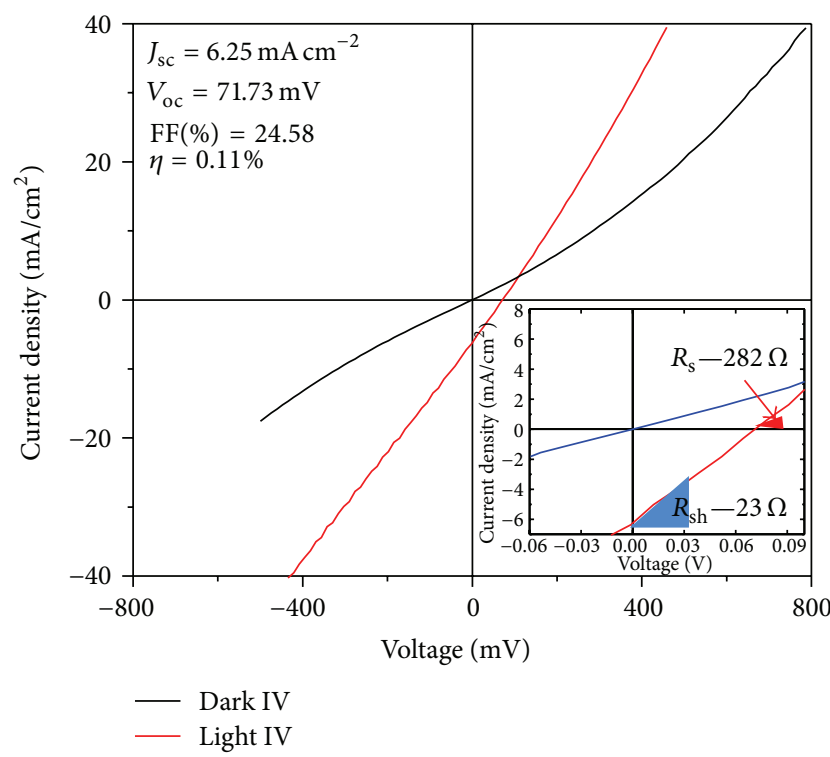

Figure 4: $J-V$ curve of CZTS thin film solar cell under dark and light irradiation.

been carried out using the cross-sectional SEM and HRTEM studies.

\subsection{Investigation of the Interfacial Properties}

3.5.1. Cross-Sectional Device Analysis. Figures 5(a) and 5(b) show the cross-sectional images of the device. The thicknesses of each layer measured using SEM and TEM images are
Mo $1.2 \mu \mathrm{m}$, CZTS $780 \mathrm{~nm}$, and CdS/ZnO/ITO $270 \mathrm{~nm}$. It was difficult to distinguish the individual layers of buffer and window layers $(\mathrm{CdS} / \mathrm{ZnO} / \mathrm{ITO})$ in the low resolution SEM/TEM. In the SEM image, CZTS grains look very compact and tightly adhered to the Mo layer as shown in Figure 5(a). The Mo back contact layer is typically grown on glass substrates by sputtering and often exhibits the columnar grain morphology as shown in Figure 5(b). The surface of the CZTS absorber layer has excellent contact with the Mo back contact which is beneficial for decreasing the minority carrier recombination and providing a current path for minority carriers to reach the n-type CdS when used in solar cell.

3.5.2. Interfacial Layer at CZTS/Mo Back Interface. Figure 6(a) shows the cross-sectional HRTEM image of CZTS/Mo interface of CZTS film deposited on Mo coated SLG by reactive cosputtering. The observed lattice spacing of $2.21 \AA$ corresponds to (110) plane of Mo [32] (Figure 6(b)). Unknown layer (green line) is observed in the CZTS region. This may be due to the formation of oxides during high temperature sintering. The observed lattice spacing of $3.36 \AA$ corresponds to (002) plane of $\mathrm{Cu}_{2} \mathrm{~S}$. Also, it is clear from Figure 6(b) that the interface between Mo and CZTS is not proper as some gap is observed, which may increase the series resistance $\left(R_{\mathrm{s}}\right)$ as well as reduce the open circuit voltage $\left(V_{\text {oc }}\right)$ of the device. The lattice spacing of about 1.92 and $2.21 \AA$ corresponds to (220) and (114) planes of CZTS $[33,34]$.

3.5.3. CZTS/CdS ( $p-n)$ Interface. Figure 7(a) shows the crosssectional HRTEM image of CZTS/CdS p-n junction interface. The observed lattice spacing of about $3.59 \AA$ corresponds 


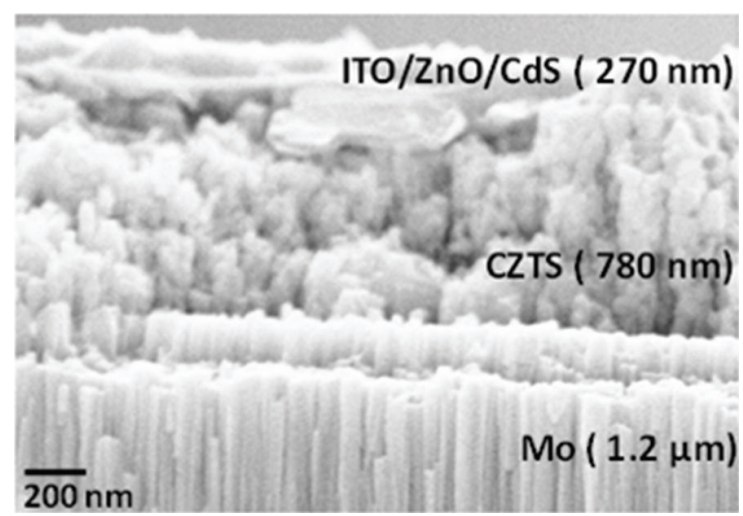

(a)

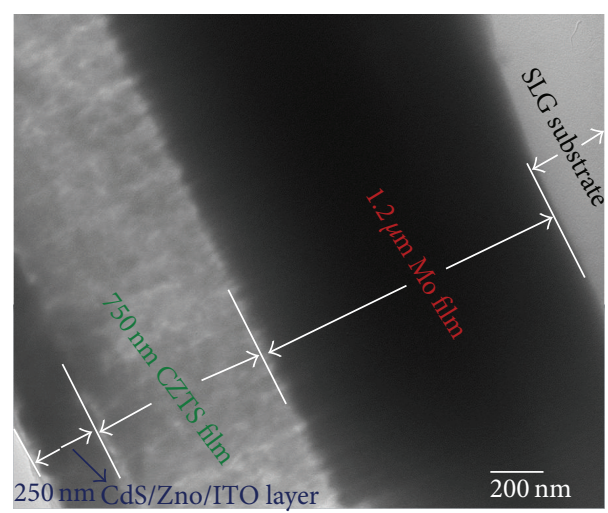

(b)

FIGURE 5: (a) Cross-sectional SEM image and (b) cross-sectional TEM image of an ITO/ZnO/CdS/CZTS/Mo film on SLG substrate.

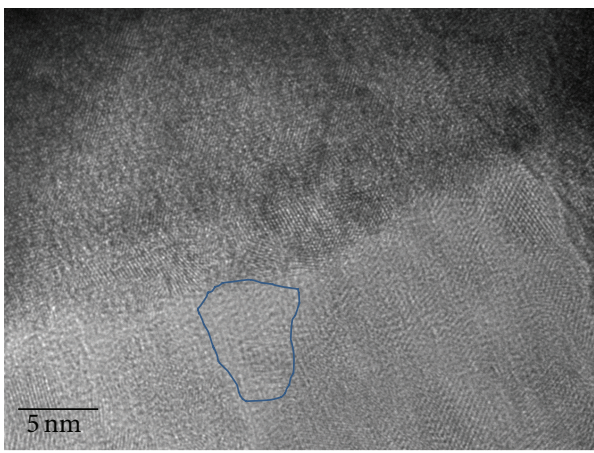

(a)

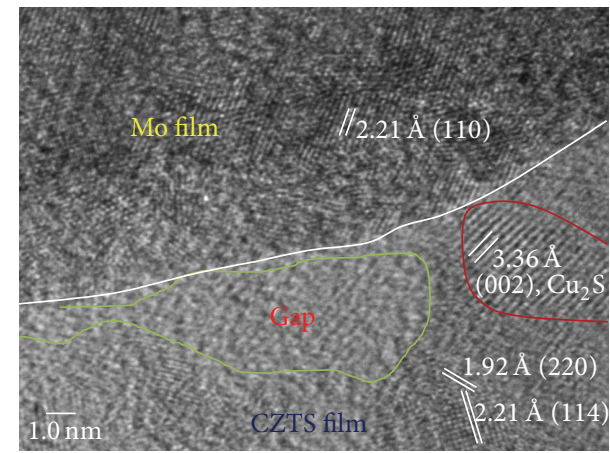

(b)

Figure 6: (a) and (b) Cross-sectional HRTEM images of CZTS/Mo back contact interfaces.

to (100) plane of CdS [35]. The lattices images show proper interaction between CZTS and CdS. The lattice spacing of about $2.01 \AA$ corresponds to (105) plane of CZTS. The observed lattice spacing of about $3.42 \AA$ corresponds to (100) plane of $\mathrm{Cu}_{2} \mathrm{~S}$. The low shunt resistance $\left(R_{\mathrm{sh}}\right)$ could be due to tunneling leakage across the $\mathrm{p}$-n junction (due to the presence of the conductive $\mathrm{Cu}_{2} \mathrm{~S}$ secondary phase).

Thus, the CZTS thin films deposited by reactive cosputtering have been characterized for their compositional, structural, optical, and electrical transport properties. A device has been made and it has been characterized thoroughly by crosssectional HRTEM and SEM. The formation of secondary phases is very harmful for thin film solar cells. However, for multinary compound materials, such as CIGS and CZTS, the formation of a secondary phase is often observed. For example, $\mathrm{Cu}_{2} \mathrm{~S}$ has been found in CZTS. TEM is a good technique to view the location of the secondary phases. This study shall fill the gap that exists on the detailed crosssectional characterization of CZTS device which is still under research state.

\section{Conclusions}

The $\mathrm{Cu}-\mathrm{Zn}$-Sn-S precursors were grown by reactive cosputtering on Mo coated SLG substrate. Annealing the precursors at around $500^{\circ} \mathrm{C}$ for 3 min provided a high quality CZTS thin film with kesterite structure. A CZTS solar cell with an efficiency of $0.11 \%$ was fabricated by depositing $\mathrm{CdS}, \mathrm{ZnO}$, ITO, and Al layers over the CZTS deposited on Mo coated SLG substrate. TEM is a good technique to view the location of the secondary phases. The formation of secondary phases is very harmful for thin film solar cells. However, for multinary compound materials, such as CIGS and CZTS, the formation of a secondary phase is possible. For example, $\mathrm{Cu}_{2} \mathrm{~S}$ has been found in CZTS. The secondary phases can often form inside the absorber materials; however, the least desirable secondary phases are those with smaller band gaps than the absorber, as these could reduce the open circuit voltage of the device and enhance recombination or worse conductive phases, which could create shorting pathways through the absorber layer. The detailed interface analysis of device has been done using the cross-sectional HRTEM. Defects have been observed in the CZTS region of the device. The studies also suggest a poor contact between Mo and CZTS which is another cause of reducing the efficiency. It could be concluded that these two factors are responsible for comparatively low efficiency in the CZTS solar cells in this work. Further, these parameters need to be optimized in order to improve the efficiency. 


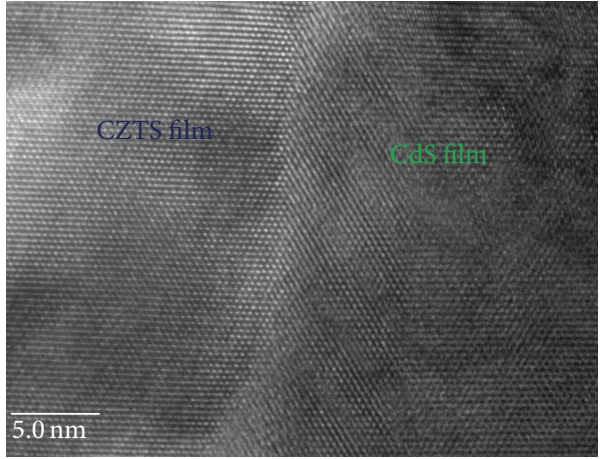

(a)

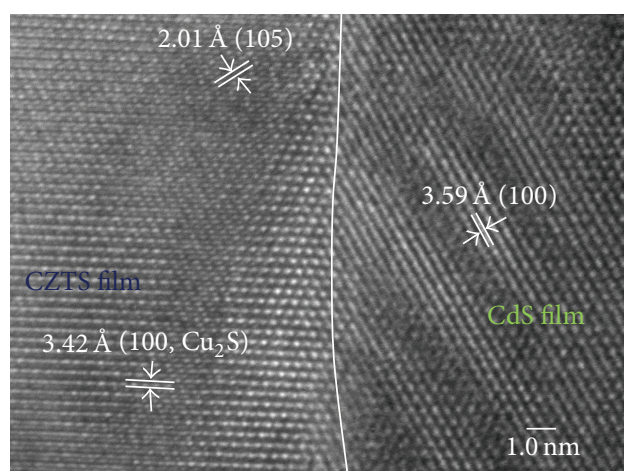

(b)

FIGURE 7: (a) and (b) Cross-sectional HRTEM images of CZTS/CdS (p-n junction) interface.

\section{Conflict of Interests}

The authors declare that there is no conflict of interests regarding the publication of this paper.

\section{Acknowledgments}

The authors are grateful to the Director of CSIR-NPL, Professor R. C. Budhani, for his close guidance in this work. They are thankful to CSIR, India, and MNRE, Government of India (Sanction number 31/29/2010-11/PVSE) for the financial support. The authors are grateful to CSIR, India, for TAPSUN Program. Om Pal Singh and N. Muhunthan are thankful to UGC for SRFships.

\section{References}

[1] H. Katagiri, N. Sasaguchi, S. Hando, S. Hoshino, J. Ohashi, and T. Yokota, "Preparation and evaluation of $\mathrm{Cu}_{2} \mathrm{ZnSnS}_{4}$ thin films by sulfurization of E-B evaporated precursors," Solar Energy Materials and Solar Cells, vol. 49, no. 1-4, pp. 407-414, 1997.

[2] J. S. Seol, S. Y. Lee, J. C. Lee, H. D. Nam, and K. H. Kim, "Electrical and optical properties of $\mathrm{Cu}_{2} \mathrm{ZnSnS}_{4}$ thin films prepared by $\mathrm{rf}$ magnetron sputtering process," Solar Energy Materials and Solar Cells, vol. 75, no. 1-2, pp. 155-162, 2003.

[3] K. Tanaka, N. Moritake, and H. Uchiki, "Preparation of $\mathrm{Cu}_{2} \mathrm{ZnSnS}_{4}$ thin films by sulfurizing sol-gel deposited precursors," Solar Energy Materials and Solar Cells, vol. 91, no. 13, pp. 1199-1201, 2007.

[4] A. I. Inamdar, S. Lee, K.-Y. Jeon et al., "Optimized fabrication of sputter deposited $\mathrm{Cu}_{2} \mathrm{ZnSnS}_{4}$ (CZTS) thin films," Solar Energy, vol. 91, pp. 196-203, 2013.

[5] A. Emrani, P. Vasekar, and C. R. Westgate, "Effects of sulfurization temperature on CZTS thin film solar cell performances," Solar Energy, vol. 98, pp. 335-340, 2013.

[6] B. Shin, O. Gunawan, Y. Zhu, N. A. Bojarczuk, S. J. Chey, and S. Guha, "Thin film solar cell with $8.4 \%$ power conversion efficiency using an earth-abundant $\mathrm{Cu}_{2} \mathrm{ZnSnS}_{4}$ absorber," Progress in Photovoltaics: Research and Applications, vol. 21, no. 1, pp. 7276, 2013.

[7] W. Wang, M. T. Winkler, O. Gunawan et al., "Device characteristics of CZTSSe thin-film solar cells with $12.6 \%$ efficiency,"
Advanced Energy Materials, vol. 4, no. 7, Article ID 1301465, 2014.

[8] T. P. Dhakal, C. Y. Peng, R. Reid Tobias, R. Dasharathy, and C. R. Westgate, "Characterization of a CZTS thin film solar cell grown by sputtering method," Solar Energy, vol. 100, pp. 23-30, 2014.

[9] The best efficiency report is currently from ZSW and corresponds to $21.7 \%$, http://www.pv-tech.org/news/zsw_sets_21.7_ cigs_cell_record.

[10] "Cadmium-Telluride (CdTe) photovoltaic (PV) solar cell conversion efficiency, achieving 20.4\%," http://investor.firstsolar .com/releasedetail.cfm?ReleaseID $=828273$.

[11] H. Katagiri, K. Jimbo, S. Yamada et al., "Enhanced conversion efficiencies of $\mathrm{Cu}_{2} \mathrm{ZnSnS}_{4}$-based thin film solar cells by using preferential etching technique," Applied Physics Express, vol. 1, no. 4, Article ID 041201, 2008.

[12] H. Katagiri, K. Saitoh, T. Washio, H. Shinohara, T. Kurumadani, and S. Miyajima, "Development of thin film solar cell based on $\mathrm{Cu}_{2} \mathrm{ZnSnS}_{4}$ thin films," Solar Energy Materials and Solar Cells, vol. 65, no. 1, pp. 141-148, 2001.

[13] S. Ahmed, K. B. Reuter, O. Gunawan, L. Guo, L. T. Romankiw, and H. Deligianni, "A high efficiency electrodeposited $\mathrm{Cu}_{2} \mathrm{ZnSnS}_{4}$ solar cell," Advanced Energy Materials, vol. 2, no. 2, pp. 253-259, 2012.

[14] F. Jiang, H. Shen, W. Wang, and L. Zhang, "Preparation and properties of $\mathrm{Cu}_{2} \mathrm{ZnSnS}_{4}$ absorber and $\mathrm{Cu}_{2} \mathrm{ZnSnS}_{4}$ /amorphous silicon thin-film solar cell," Applied Physics Express, vol. 4, no. 7, Article ID 074101, 2011.

[15] A. Ennaoui, M. Lux-Steiner, A. Weber et al., " $\mathrm{Cu}_{2} \mathrm{ZnSnS}_{4}$ thin film solar cells from electroplated precursors: novel low-cost perspective," Thin Solid Films, vol. 517, no. 7, pp. 2511-2514, 2009.

[16] A. Walsh, S. Chen, S.-H. Wei, and X.-G. Gong, "Kesterite thinfilm solar cells: Advances in materials modelling of $\mathrm{Cu}_{2} \mathrm{ZnSnS}_{4}$," Advanced Energy Materials, vol. 2, no. 4, pp. 400-409, 2012.

[17] S. Chen, X. G. Gong, A. Walsh, and S.-H. Wei, "Defect physics of the kesterite thin-film solar cell absorber $\mathrm{Cu}_{2} \mathrm{ZnSnS}_{4}$," Applied Physics Letters, vol. 96, no. 2, Article ID 021902, 2010.

[18] S. Chen, A. Walsh, X.-G. Gong, and S.-H. Wei, "Classification of lattice defects in the kesterite $\mathrm{Cu}_{2} \mathrm{ZnSnS}_{4}$ and $\mathrm{Cu}_{2} \mathrm{ZnSnSe}_{4}$ earth-abundant solar cell absorbers," Advanced Materials, vol. 25, no. 11, pp. 1522-1539, 2013.

[19] O. Gunawan, T. K. Todorov, and D. B. Mitzi, "Loss mechanisms in hydrazine-processed $\mathrm{Cu}_{2} \mathrm{ZnSn}(\mathrm{Se}, \mathrm{S})_{4}$ solar cells," Applied Physics Letters, vol. 97, no. 23, Article ID 233506, 2010. 
[20] T. Gokmen, O. Gunawan, T. K. Todorov, and D. B. Mitzi, "Band tailing and efficiency limitation in kesterite solar cells," Applied Physics Letters, vol. 103, no. 10, Article ID 103506, 2013.

[21] F. Liu, Y. Li, K. Zhang et al., "In situ growth of $\mathrm{Cu}_{2} \mathrm{ZnSnS}_{4}$ thin films by reactive magnetron co-sputtering," Solar Energy Materials and Solar Cells, vol. 94, no. 12, pp. 2431-2434, 2010.

[22] J. B. Li, V. Chawla, and B. M. Clemens, "Investigating the role of grain boundaries in CZTS and CZTSSe thin film solar cells with scanning probe microscopy," Advanced Materials, vol. 24, no. 6, pp. 720-723, 2012.

[23] J. J. Scragg, T. Ericson, X. Fontané et al., "Rapid annealing of reactively sputtered precursors for $\mathrm{Cu}_{2} \mathrm{ZnSnS}_{4}$ solar cells," Progress in Photovoltaics: Research and Applications, vol. 22, no. 1, pp. 10-17, 2014.

[24] O. P. Singh, N. Muhunthan, V. N. Singh, and B. P. Singh, "Effect of annealing time on the composition, microstructure and band gap of copper zinc tin sulfide thin films," Advanced Materials Letters, 2014.

[25] O. P. Singh, N. Muhunthan, V. N. Singh, K. Samanta, and N. Dilawar, "Effect of temperature on thermal expansion and anharmonicity in $\mathrm{Cu}_{2} \mathrm{ZnSnS}_{4}$ thin films grown by co-sputtering and sulfurization," Materials Chemistry and Physics, vol. 146, no. 3, pp. 452-455, 2014.

[26] K. Ito and T. Nakazawa, "Electrical and optical properties of stannite-type quaternary semiconductor thin films," Japanese Journal of Applied Physics, vol. 27, no. 11, pp. 2094-2097, 1988.

[27] N. Muhunthan, O. P. Singh, S. Singh, and V. N. Singh, "Growth of CZTS thin films by cosputtering of metal targets and sulfurization in $\mathrm{H}_{2} \mathrm{~S}$, International Journal of Photoenergy, vol. 2013, Article ID 752012, 7 pages, 2013.

[28] F. Jiang, H. Shen, J. Jin, and W. Wang, "Preparation and optoelectronic properties of $\mathrm{Cu}_{2} \mathrm{ZnSnS}_{4}$ film," Journal of the Electrochemical Society, vol. 159, no. 6, pp. H565-H569, 2012.

[29] T. Tanaka, T. Nagatomo, D. Kawasaki et al., "Preparation of $\mathrm{Cu}_{2} \mathrm{ZnSnS}_{4}$ thin films by hybrid sputtering," Journal of Physics and Chemistry of Solids, vol. 66, no. 11, pp. 1978-1981, 2005.

[30] J. C. Gonzalez, G. M. Ribeiro, E. R. Viana et al., "Hopping conduction and persistent photoconductivity in $\mathrm{Cu}_{2} \mathrm{ZnSnS}_{4}$ thin films," Journal of Physics D: Applied Physics, vol. 46, no. 15, Article ID 155107, 2013.

[31] M. Z. Ansari and N. Khare, "Structural and optical properties of CZTS thin films deposited by ultrasonically assisted chemical vapour deposition," Journal of Physics D: Applied Physics, vol. 47, no. 18, Article ID 185101, 2014.

[32] S. J. Wang, H. Wang, K. Du, W. Zhang, M. L. Sui, and S. X. Mao, "Deformation-induced structural transition in bodycentred cubic molybdenum," Nature Communications, vol. 5, article 3433, 2014.

[33] C.-H. Ruan, C.-C. Huang, Y.-J. Lin, G.-R. He, H.-C. Chang, and Y.-H. Chen, "Electrical properties of $\mathrm{Cu}_{x} \mathrm{Zn}_{y} \mathrm{SnS}_{4}$ films with different $\mathrm{Cu} / \mathrm{Zn}$ ratios," Thin Solid Films, vol. 550, pp. 525-529, 2014.

[34] S. Sarkar, K. Bhattacharjee, G. C. Das, and K. K. Chattopadhyay, "Self-sacrificial template directed hydrothermal route to kesterite- $\mathrm{Cu}_{2} \mathrm{ZnSnS}_{4}$ microspheres and study of their photo response properties," CrystEngComm, vol. 16, no. 13, pp. 26342644, 2014.

[35] D. Lang, Q. Xiang, G. Qiu, X. Feng, and F. Liu, "Effects of crystalline phase and morphology on the visible light photocatalytic $\mathrm{H}_{2}$-production activity of CdS nanocrystals," Dalton Transactions, vol. 43, no. 19, pp. 7245-7253, 2014. 


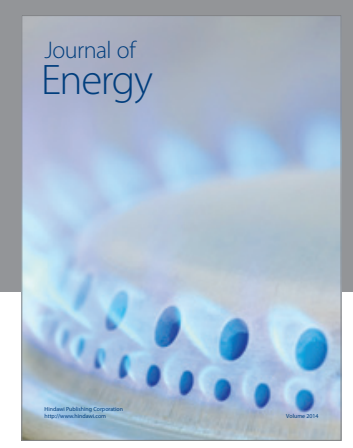

Journal of

Industrial Engineering
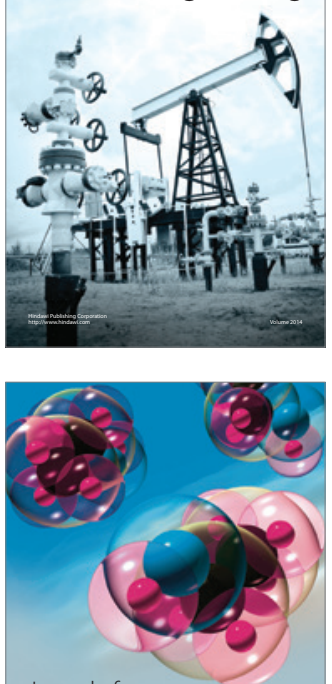

Fuels
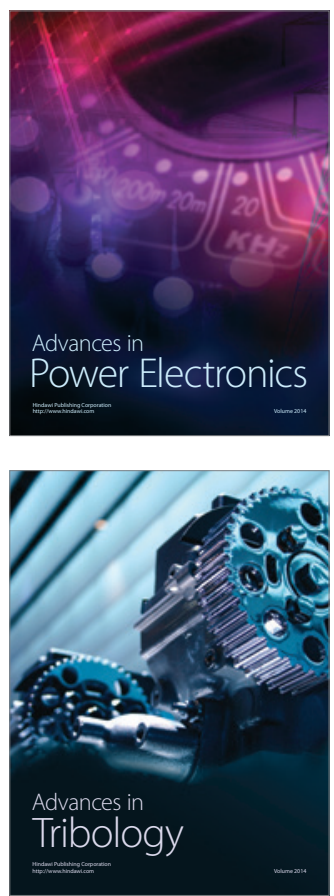

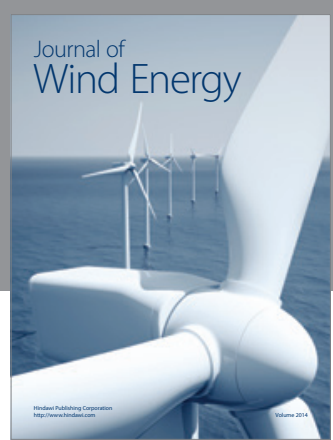

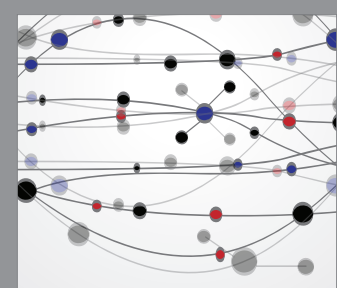

The Scientific World Journal

Submit your manuscripts at http://www.hindawi.com

Journal of

Structures
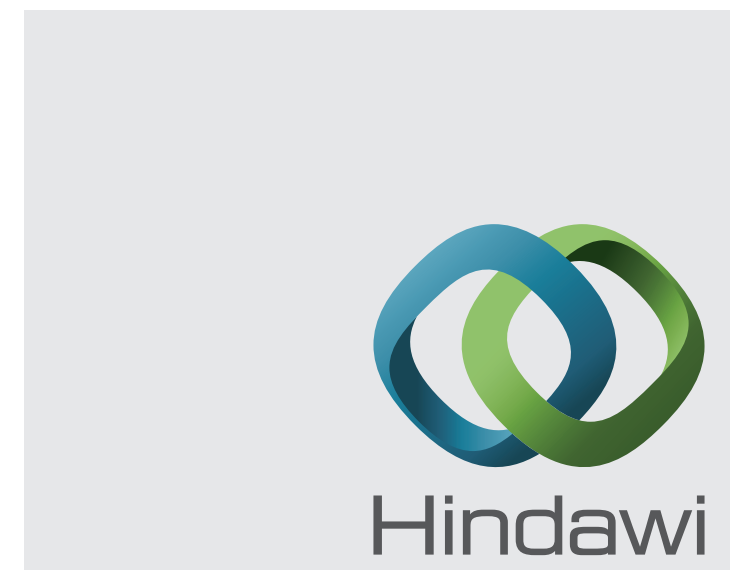

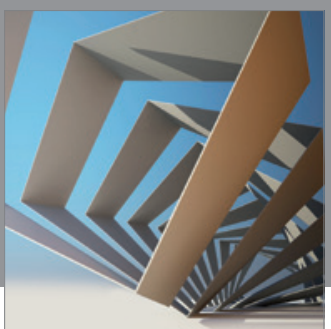

Rotating

Machinery
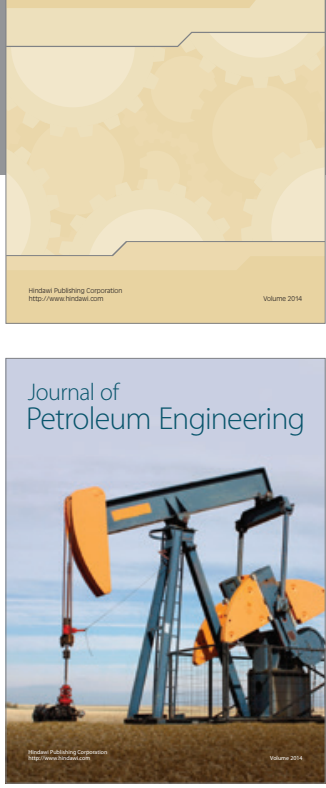

Journal of

Solar Energy
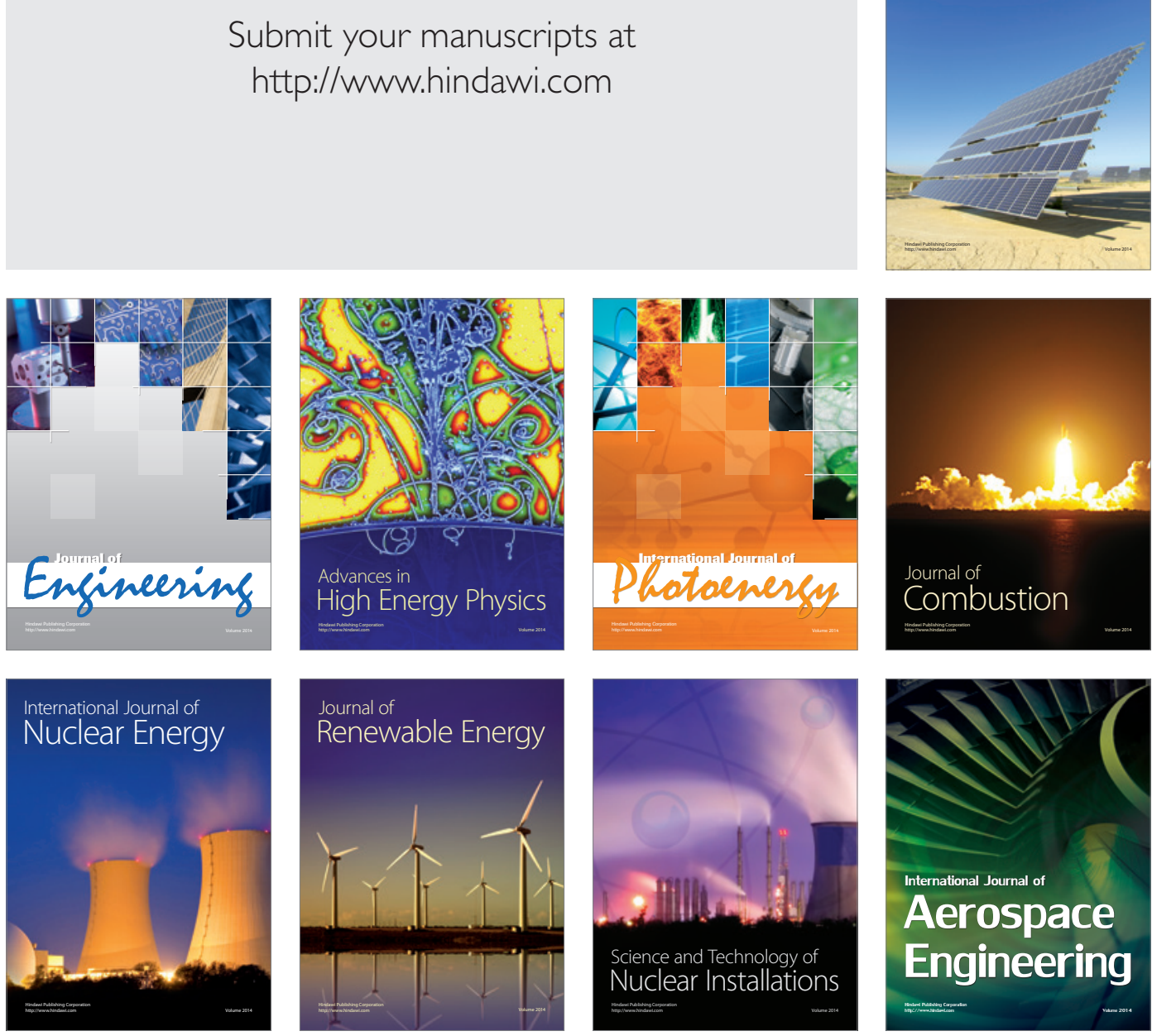